\title{
So you want to be an editor
}

\author{
Paul C Adams MD, FRCPC, Editor-in-Chief
}

A 11 things must pass, and as I approach the end of my term as Editor-in-Chief, I thought I would prepare some guidelines and advice for potential candidates to be the next Editor-in-Chief.

\section{Stature}

The ideal Editor should be in mid-career, command a national respect and have a broad range of international contacts. This is because the Editor must be able to entice writers and reviewers, and be able to form a team around the Editor. The Editor will likely be a prominent gastroenterologist with connections to academic medicine but with a foothold in clinical practice. The focus of the Editor may come from any aspect of gastroenterology and hepatology but not to the exclusion of the broad range of subjects that may be appropriate for The Canadian Journal of Gastroenterology. The are no age restrictions associated with this position, but an age range of 45 to 55 years may be preferable to a retiring physician.

\section{Leadership}

The ideal Editor will have leadership experience at their institution, or on a national or international stage. There are a number of challenges that face a journal Editor, including submission deadlines, cycles of low submissions, late and absent reviewers, pharmaceutical company influences and ultimately, delivery of a product that is pleasing to all parties including the Canadian Association of Gastroenterology (CAG) and Canadian Association for the Study of the Liver (CASL) members, Pulsus Group, advertisers and the many nongastroenterology physicians that receive the Journal.

\section{Integrity}

The ideal Editor will have a strong sense of ethics because influence from the pharmaceutical industry and other conflicts of interest can arise almost on a daily basis.

\section{Availability}

The Editor must never be more than a day away from the Internet because the Journal is a living and evolving process. The Editor must be very familiar with computing, typing, e-mail and the Internet. This is not a position that can be designated to a secretary. A working knowledge of statistics and graphic design are helpful assets.

\section{Tempo}

The ideal Editor has an internal clock that is tightly wound and has their finger on the Journal's pulse on a daily basis.

\section{Creativity}

The Journal can be a creative environment, which is one of the most attractive aspects of the position. It is a contrast to the stifling atmosphere of many hospitals and academic departments. This flexibility can allow the flair of the Editor to unfold into something new and beneficial to our readership. The previous four Editors of the Journal have brought diverse backgrounds, interests and peer-groups with them. Each Editorship brings a different management style and vision, and this constant renewal can bring the Journal to new heights.

\section{Reimbursement}

The Editor receives a stipend per issue from Pulsus. This does not translate into a great hourly wage but it does offset some of the time that is committed by the Editor to the Journal. The Editor should consider a component of the job to be a community service to the CAG/CASL and the readership.

\section{Editor selection process}

A Selection Committee that is chaired by Dr Craig Render has been formed. It includes both CAG and CASL representatives. The position will be advertised in the summer of 2009, the Editor will be selected in the autumn of 2009 and will begin in January 2010. A three-month transition will overlap with the existing Editor.

The Canadian Journal of Gastroenterology is at an all-time high for Pulsus journals, with an impact factor of 2.11. We have reconnected with our readership of clinical gastroenterologists and hepatologists. The current editorial team is delighted with the progress of the Journal and we have learned and grown together as a team. While we are proud of our changes and direction in the Journal, we would expect and anticipate a new vision and approach with the next editorial team. When the composer John Cage was asked about his favorite music, he simply stated that it was the music he had not heard yet - the best is yet to come. 


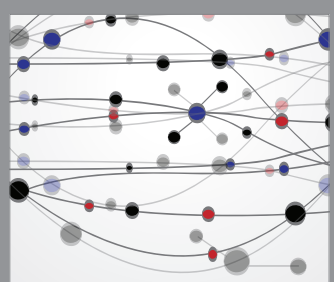

The Scientific World Journal
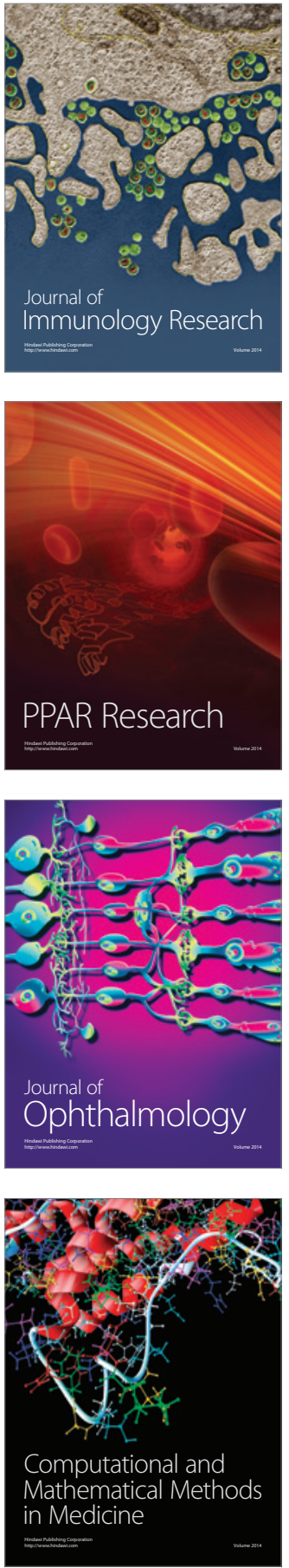

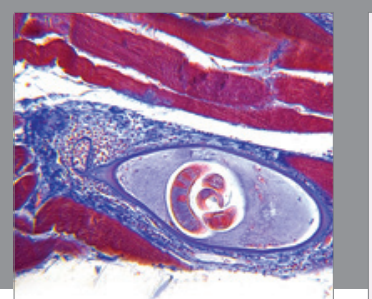

Gastroenterology Research and Practice

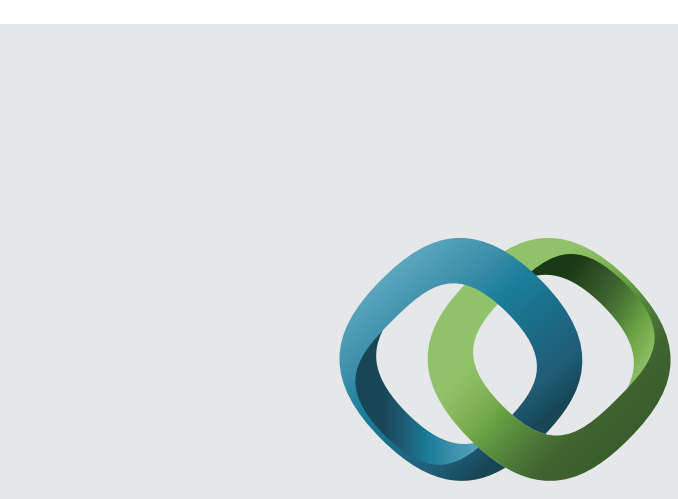

\section{Hindawi}

Submit your manuscripts at

http://www.hindawi.com
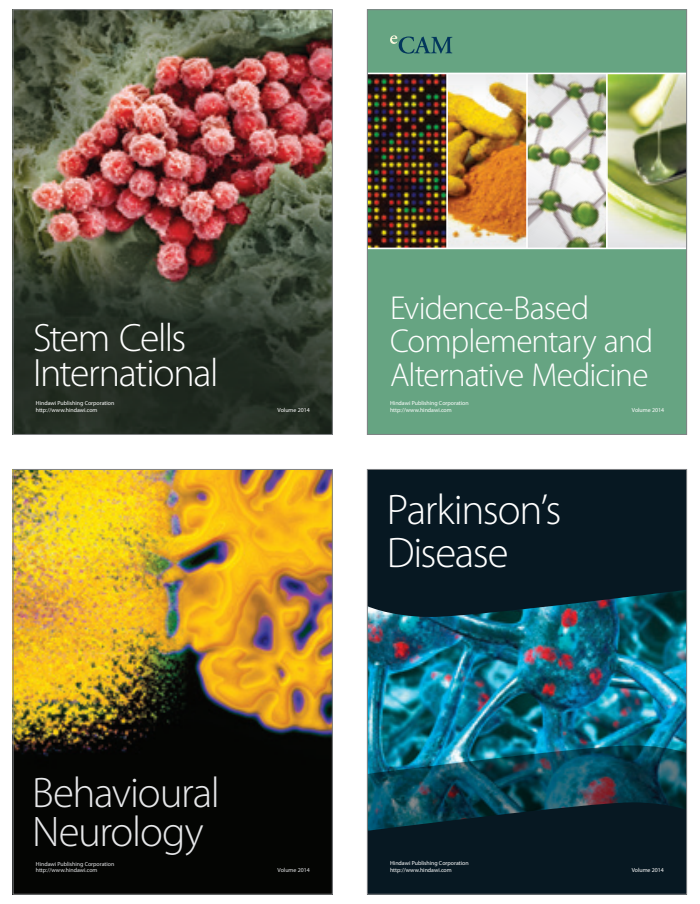
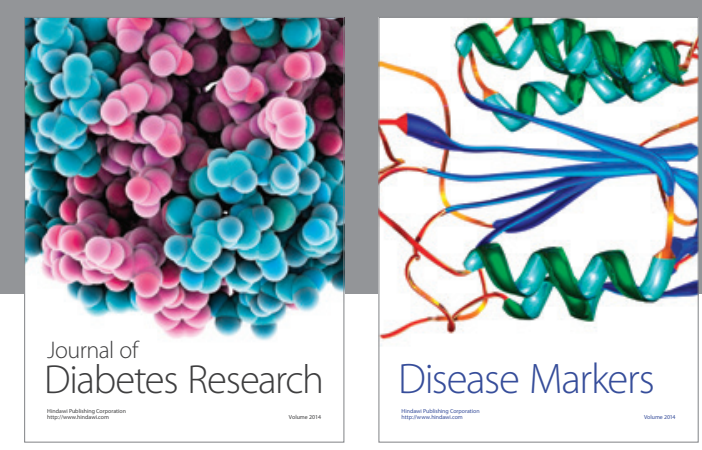

Disease Markers
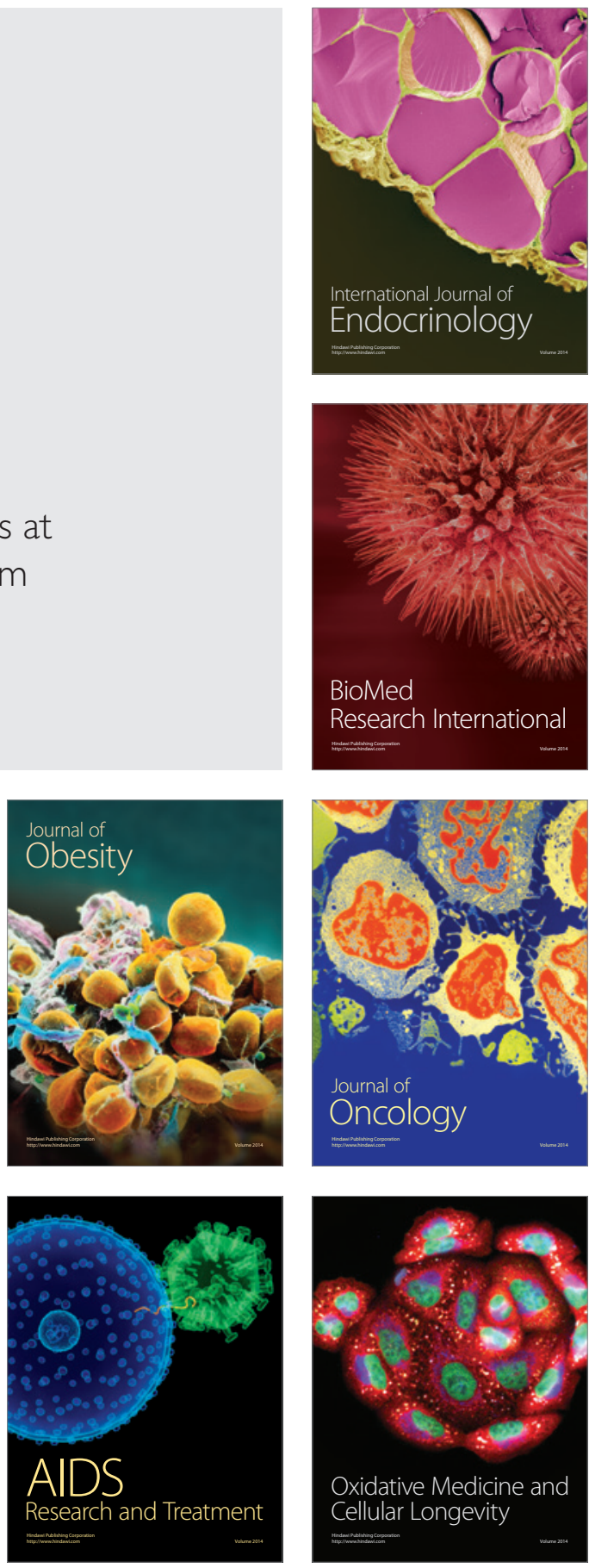